\title{
Willful Ignorance and Bad Motives
}

\author{
Jan Willem Wieland ${ }^{1}$
}

Received: 24 August 2016/Accepted: 2 May 2018/Published online: 6 June 2018

(C) The Author(s) 2018

\begin{abstract}
Does willful ignorance mitigate blameworthiness? In many legal systems, willfully ignorant wrongdoers are considered as blameworthy as knowing wrongdoers. This is called the 'equal culpability thesis' (ECT). Given that legal practice depends on it, the issue has obvious importance. Interestingly enough, however, there exists hardly any philosophical reflection on ECT. A recent exception is Alexander Sarch, who defends a restricted version of ECT. On Sarch's view, ECT is true whenever willfully ignorant agents incur additional blameworthiness for their ignorance. In this paper, I defend an alternative view, according to which ECT is true whenever the motives of willfully ignorant and knowing wrongdoers are equally bad.
\end{abstract}

\section{Introduction}

Consider the following three cases:

Tourist. Will is a tourist, and when he is about to leave for his holiday destination a stranger offers him $\$ 2000$ to deliver a suitcase abroad. The stranger looks friendly, and although Will suspects that something might be wrong with the contents of the suitcase, he keeps himself willfully ignorant by not asking any questions. He tells himself that it might well contain gifts for the stranger's family and accepts the offer. Unknown to him, the suitcase contains weapons. Noah is very similar to Will, and receives and accepts the same offer, though in contrast

Jan Willem Wieland

j.j.w.wieland@vu.nl

1 Department of Philosophy, VU University Amsterdam, De Boelelaan 1105,

1081 HV Amsterdam, The Netherlands 
to Will he does ask about the contents of the suitcase, and knows full well he is transporting weapons.

Conductor. Will lives during World War II and helps the Nazis as the conductor of a transport train. He doesn't know about the Holocaust, because he keeps himself willfully ignorant by not asking any questions. He suspects that something might be wrong about his work, but he doesn't know that he transports people to concentration camps. Noah is very similar to Will, and does the same kind of work for the Nazis. In contrast to Will, however, Noah doesn't fool himself. He asks about the passengers, and knows full well he's transporting people to concentration camps.

Flyer. Will is a frequent flyer. Every weekend, he flies to another city to spend his free time abroad. Of course, he has heard people make claims about climate change, but he doesn't really know whether they are true since he keeps himself willfully ignorant by not reading any newspapers and not looking into joining a carbon offset program. He suspects that something might be wrong about his lifestyle, but he doesn't know that he contributes to climate change. Noah is very similar to Will, and leads a very similar party life, though unlike Will he knows full well about his ecological footprint.

As always, cases can be read in different ways. Here, the cases are meant to be structurally similar. ${ }^{1}$ In all three cases, there is a knowing wrongdoer, Noah, and a willfully ignorant wrongdoer, Will. They engage in the same behaviour (transporting weapons, helping the Nazis, frequent flying), yet with a difference: Noah knows what he is doing. By contrast, Will does not know what he is doing. He merely suspects that his conduct might be wrong. He does know that he could inform himself better, but willfully avoids doing so. ${ }^{2}$

The question we'll consider in what follows is: who is more blameworthy? On the one hand, Noah seems more blameworthy given that he knows what he is doing. On the other hand, Will seems no less blameworthy, since he could easily inform himself better and knows he could do so. Is Noah more blameworthy than Will, or are they blameworthy to the same degree?

In many legal systems, the latter view is accepted. At least when it comes to transporting drugs, one's willful ignorance will provide no excuse and does not mitigate one's blameworthiness. Husak and Callender (1994) have dubbed this the 'equal culpability thesis' (ECT). Following Husak and Callender, one may wonder why ECT should hold. Given that legal practice depends on it (at least partially), the issue has obvious importance. Interestingly enough, ECT has hardly been defended in the literature. A recent exception is Sarch $(2014,2016)$, who defends a restricted version of it. Further philosophical reflection on ECT is called for. This paper

\footnotetext{
${ }^{1}$ Examples can easily be multiplied, cf. Moody-Adams (1994).

2 For the purposes of this paper, I'll assume that an agent $\mathrm{S}$ is willfully ignorant that her conduct is wrong if: $\mathrm{S}$ does not know this, but merely suspects it, and $\mathrm{S}$ knows she could take reasonable steps to inform herself, but chooses not to take these steps. I follow Husak and Callender (1994: 41-53) and Sarch (2014: 1048-1052) in assuming that willful ignorance does not amount to knowledge. I follow Sarch (2014: 1047), and differ from Husak and Callender (1994), in assuming that willful ignorance is compatible with various motives for remaining ignorant (see Sect. 3 below).
} 
proposes an alternative to Sarch's account. The plan is straightforward. In Sect. 2, I'll summarize Sarch's proposal. In Sect. 3, I'll extend an aspect of Sarch's approach. In Sects. 4, 5 and 6, I'll set forth and defend my alternative.

Before proceeding, three comments are in order. First, it should be noted that the question "who is more blameworthy?" is ambiguous between a scope and degree reading. ${ }^{3}$ Scope reading: which agent is blameworthy for more things? Degree reading: which agent is blameworthy to a greater degree? Clearly, the latter question is the relevant one in this context. Will may be blameworthy for more things (namely, not only for his ignorant act, but also for his ignorance), but that is not what we want to know. What we want to know is his degree of blameworthiness (i.e. for his overall conduct), and whether it is as high as Noah's. In the following, the degree reading will be implicit.

Second, apart from issues regarding knowledge and ignorance, the cases of Will and Noah are supposed to be similar in all other relevant aspects. For one thing, in all cases the conduct of the agents is regarded as morally wrong (even though, apart from Tourist, it may not be illegal). It is wrong for both tourists to transport weapons, for both conductors to help the Nazis, and for both flyers to live their lifestyle. Let us also assume that both agents in each case have reasonable opportunities to act otherwise. In Tourist, neither of the agents really need the money. In Conductor, both agents have alternative job options (and we may also assume that if enough conductors were to take different jobs, the rate of transport would be much slower). In Flyer, both agents can live an excellent life in their hometown as well. (We may also suppose that both agents lack such alternate possibilities; what matters, again, is that Will and Noah are similar in all other relevant respects.)

Finally, ECT may be read in terms of legal punishment as well as in terms of moral blameworthiness. ${ }^{4}$ There is the question of whether or not Will and Noah should be legally punished in the same way, and there is the question of whether they deserve equal blame for what they have done. To some extent, the former question concerning legal punishment depends on the latter question concerning moral blameworthiness, though of course legal punishment serves other purposes as well. Apart from giving wrongdoers what they deserve, we may punish them in order to rehabilitate them, to deter others from committing similar crimes, or to protect society from them. In this paper, we will abstract from these forwardlooking issues and focus exclusively on the backward-looking question of whether or not Will and Noah are equally blameworthy for what they did.

\section{Sarch's Account}

Next, I'll summarize Sarch's defense of ECT (or at least a restricted version of it). Basically, in order to defend or criticize ECT, one needs a principle on the basis of which knowing wrongdoers and willfully ignorant wrongdoers can be compared.

\footnotetext{
${ }^{3}$ For this distinction, cf. Zimmerman (1988: 133-134).

4 'Blameworthiness' and 'culpability' are treated as equivalent terms.
} 
Sarch starts from the following principle, which he calls the 'comparative culpability principle' $(\mathrm{CCP})^{5}$ :

For any two people who commit the actus reus of a crime, if they are identical in all respects except that one is more confident in the truth of the inculpatory proposition, $\mathrm{p}^{6}$ than the other, then - assuming there are no relevant excuses or justifications, and all else is equal - the person with the greater degree of confidence in $\mathrm{p}$ is more culpable than the one with the lesser degree of confidence. (2014: 1062-1063)

To illustrate, Sarch uses the following example. Suppose there are two very similar agents who set a building on fire. The only difference between these agents is that the first is fairly confident that a person is inside, while the second is far less confident about this (she is merely aware of a certain risk that someone might be inside). Intuitively, the first agent is more blameworthy for setting the building on fire (and killing the person, if there were indeed a person in the building) than the second agent. CCP yields exactly such a result.

Sarch's question is this: how can ECT be true in light of CCP? After all, based on this principle knowing wrongdoers should be considered more culpable (or blameworthy) than willfully ignorant wrongdoers. In Tourist, for example, Noah has more confidence in the truth of the proposition that he is transporting weapons than Will does. Noah knows what he is doing, while Will only suspects that something might be wrong.

Moreover, Sarch accepts that Will is less blameworthy than Noah for his ignorant act (given CCP). Yet, Sarch adds that Will might incur additional blameworthiness for his ignorance and for "breaching a duty of investigation". When Will does incur such additional blameworthiness, then, even if his degree of blameworthiness for his ignorant act is lower than Noah's (for example, Will is less blameworthy for transporting the weapons than Noah), his overall degree of blameworthiness (that is, for his failure to inform himself and his ignorant act taken together) might still be as high as Noah's overall degree of blameworthiness. ${ }^{7}$

For obvious reasons, let's call Sarch's account the 'Compositional Account'. The Compositional Account constitutes a restricted defense of ECT. As Sarch points out, sometimes willfully ignorant agents incur enough additional blameworthiness for their ignorance that, overall, they are as blameworthy as knowing wrongdoers. But this is not always the case. Sometimes willfully ignorant agents do not incur much additional blameworthiness for their ignorance. As Sarch explains: "the willfully ignorant actor's decision not to investigate whether $\mathrm{p}$ is true can be made for a variety of reasons, some of which can render one more culpable than others" (2014: 1065). One of his examples:

\footnotetext{
5 Cf. Simons (2002: 251) for a similar principle.

6 Examples of 'p': the proposition that there are weapons in one's suitcase, that the Nazis will kill one's passengers, that one's ecological footprint is considerable.

7 Or even higher, if the willfully ignorant agent's motives are really bad, compared to the motives of the knowing wrongdoer. I consider a few relevant examples in Sect. 3 below.
} 
Overly Trusting Parent. Patty and her adult child, Charles, had gone through a long period of estrangement due to Charles's trouble with the law, and they were only recently reconciled. Thus, Patty is very concerned to rebuild trust with her child. When Charles one day asks Patty to drive a sealed crate across town to a friend of his, Patty decides not to look inside. She considers the risk that the crate might contain some kind of contraband (whether drugs, weapons, or stolen property), and she strongly desires not to take part in any illegal activity. But after much agonizing, she chooses not to open the crate or ask Charles to do so because this sign of mistrust would irrevocably damage their recently repaired relationship. And so she sets off across town with the crate in the trunk. On the way, she is pulled over by the police and it turns out the crate contains drugs. (2014: 1066-1067)

In this case, Patty declines to ask questions about the contents of the crate only because she does not want to damage the relationship with her child. According to Sarch, such a motive is not sufficiently bad, and does not render her as blameworthy as a comparable agent who is motivated by worse reasons. Sarch does not provide a full overview of such reasons, but he does identify two of them: S's motive for not investigating $\mathrm{p}$ is sufficiently bad if S wants to "preserve a defense against liability", or if S wants to "perpetuate, protect, or continue to receive the benefits of a suspected conspiracy or other criminal conduct" (2014: 1100). ${ }^{8}$ So, Patty's motive would have been worse if she had wanted to preserve a defense against liability for the transport of drugs, or if she were somehow interested in the benefits of the transport. ${ }^{9}$

The question arises here of how much additional blameworthiness agents might incur for their ignorance. Sarch (2014: 1086-1088) points out that he has no comprehensive view on how to calculate this, though he does make four remarks on the issue. First, the easier it is to inform oneself, the greater one's degree of blameworthiness for not doing so. Second, consciously deciding not to inform oneself renders one more blameworthy than would forgetting or negligently omitting to do so. Third, one's reasons for not informing oneself can render one more or less blameworthy. Generally, Sarch suggests, the more one's reasons manifest a disregard for the interests of others (for example, for the passengers one is transporting in Conductor), the greater one's degree of blameworthiness. Finally, whether one's conduct constitutes a major or minor wrong is irrelevant (whether the agent is transporting people to concentration camps or merely drugs) given that we are only interested in pairs of agents who engage in similar conduct.

Sarch's account is an improvement on existing legal systems (insofar as the latter track moral blameworthiness). ${ }^{10}$ In many systems, motives for remaining ignorant

\footnotetext{
${ }^{8}$ For the first reason, cf. Husak and Callander (1994: 40). It is not immediately clear how the second reason is a reason for remaining ignorant, though arguably the idea is that committing crimes in ignorance is easier, or less inconvenient, than committing them knowingly.

9 Agents might be motivated by different reasons at the same time. In that case, their blameworthiness is a function of the strength of the whole configuration of reasons for which they act.

${ }^{10}$ See Sarch (2014) for the references to these systems. Even if in many of these systems motives do not affect the seriousness of the offense for which one is convicted, they might still affect the actual sentence the court imposes.
} 
are wholly irrelevant. Willfully ignorant wrongdoers are always considered equally blameworthy to knowing wrongdoers, no matter their exact motives. These systems seem overinclusive, for they will punish Patty in the case just discussed to the same degree as a comparable agent who knows what she is doing. Other legal systems only recognize the motive of preserving a defense against liability, and will only punish willfully ignorant agents with this motive. These systems seem underinclusive (and arbitrary), for they fail to punish willfully ignorant agents with other bad motives such as the motive of protecting the benefits of criminal conduct.

In this respect, Sarch's account is quite sensible. In my view, however, the proposal itself is unsatisfactory. As Sarch himself admits, his remarks on blameworthiness for ignorance do not follow from a comprehensive principle. First, there might be more patterns that correlate with blameworthiness for ignorance. Not only might information be more or less accessible to $\mathrm{S}$, but also $\mathrm{S}$ might exert more or less effort to avoid it. And S might not only more or less consciously and deliberately ignore information, but she might also have stronger or weaker suspicions that she should better inform herself. Also, she might find informing herself more or less convenient due to psychological barriers (for which she may or may not be responsible). Any of these factors could be relevant.

Second, and most importantly, one might wonder why and in what way these factors matter. For example, why would the accessibility of information covary with one's degree of blameworthiness? The absence of such an explanation is a disadvantage of Sarch's account. In the alternative account to be presented in what follows, I will develop a comprehensive principle in terms of bad motives, and discuss further explications of this principle. This account is fundamentally different from Sarch's, as I will explain, since it denies the idea of the composition of blameworthiness. Before arguing for these points, and presenting my NonCompositional Account, I will extend Sarch's approach on one important point.

\section{Ambiguities}

Cases such as Sarch's Overly Trusting Parent discussed in the previous section suggest that much depends on the motives of knowing and willfully ignorant wrongdoers. ${ }^{11}$ Yet, while Sarch applies this idea only to willfully ignorant wrongdoers (for a selected number of motives), I will argue that the same applies to knowing wrongdoers (and also expand the range of motives). Indeed, we can't evaluate ECT if we focus only on willfully ignorant wrongdoers. If two agents are equally blameworthy, and their blameworthiness is a function of their motives (at least in part), we have to examine the motives of both of them. Basically, I will show that all of the Will and Noah cases from Sect. 1 are ambiguous and can be spelled out in different ways. Moreover, in these variants

\footnotetext{
11 The difference between Patty and her more blameworthy counterparts cannot be explained only in terms of a difference in motives, but also in terms of a difference in justifications for remaining ignorant. For more on the latter, cf. Hellman (2009) and Sarch (2016).
} 
the agents do not seem to have equally bad motives (which will complicate any discussion of ECT). ${ }^{12}$

Let us first consider Will. Again, the relevant question is why he avoids information, which he might have done for a variety of reasons: (1) he wants to preserve a defense against liability, (2) he wants to preserve his lifestyle, (3) he cannot handle the truth, (4) he is just lazy, or (5) he was simply confused at the time. ${ }^{13}$

We have already seen (1) and (2), and it is instructive to contrast these with (3)(5). In most Tourist cases, Will does not ask any questions because he wants to preserve a defense against liability (example of (1)). On a natural reading of Flyer, Will does not ask any questions because he wants to preserve his party life, and this is more convenient when he is ignorant about his footprint than when he knows about it $((2))$. In a natural variant of Conductor, Will does not ask any questions because he cannot handle the truth about his transport ((3)). Will might also fail to ask questions because he is just lazy. In such cases, he does not care much about informing himself generally, and this has little to do with any of the motives just mentioned ((4)). Or else perhaps Will was just confused at the time, even though we might suppose he would have informed himself in a majority of similar cases ((5)).

In my view, Noah is similarly ambiguous. As described, Noah knows what he is doing, but this description fits quite different agents. He might know what he is doing, but (6) still be ignorant that it is wrong (or illegal), or (7) that it is wrong on balance, or he does know that his conduct is wrong (on balance), but (8) he lacks the strength to do the right thing, or (9) he does not care about it, or (10) he wants to do the wrong thing.

Examples of (6): in Conductor, Noah is a Nazi himself, and believes he is doing the right thing by transporting people to concentration camps; or in Flyer, Noah is a climate change denier, and believes that frequent flying is permissible. Examples of (7) are all over the place: in Tourist, Noah knows that weapons are bad, but tells himself that they will be used for good purposes (for security, say); in Conductor, Noah knows he is transporting people to concentration camps, but tells himself the camps cannot be all that bad; in Flyer, Noah knows about his footprint, but tells himself that he deserves the flights. In all these cases, Noah knows that something is wrong about his conduct, but he believes that there are overriding reasons to do it anyway, and he is still ignorant that his conduct is wrong on balance. Examples of (8)-(10) are less common, though still quite conceivable. Noah knows that he is transporting people to concentration camps and that this is wrong, and he does not really want to do the wrong thing, but he is weak and cannot bring himself to quit his job (an example of (8)). ${ }^{14} \mathrm{He}$ knows that he is transporting people to

\footnotetext{
12 In the following, I won't assume that S's motives are always fully transparent to S, i.e. that $S$ can always report on her motives. For example, one may be motivated by a desire to preserve one's lifestyle even though this may not be obvious to oneself (and one may not be willing to admit it, cf. Wieland 2017a). What I am interested in are facts about agents that explain their conduct.

13 Husak and Callender (1994) wouldn't count (3)-(5) as cases of willful ignorance because these motives aren't sufficiently bad. Yet, this simply shifts the focus to our upcoming question, namely: which motives are bad?.

14 If weakness of will exists, this should be an example of it.
} 
concentration camps and that this is wrong, but he could not care less ((9)). Or: Noah knows that he is transporting people to concentration camps and that this wrong, but he wants precisely to do the wrong thing ((10)).

I have just distinguished quite different variants of Tourist, Conductor, and Flyer (the list is not meant to be exhaustive). On the face of it, the agents in these variants do not have equally bad motives and do not seem equally blameworthy. For example, Noah who acts from a weak will ((8)) does not seem as blameworthy as Noah who acts from a bad will ((10)). This means that ECT, as a general claim that all similarly situated pairs of Noahs and Wills are equally blameworthy, is rather dubious.

\section{Non-compositional Alternative}

I will accept that ECT might be correct in certain cases. That is, sometimes willfully ignorant wrongdoers are as blameworthy as knowing wrongdoers. In such cases, ECT holds not because willfully ignorant wrongdoers incur additional blameworthiness for their ignorance, as Sarch's Compositional Account has it, but simply because the motives of willfully ignorant wrongdoers are as bad as the motives of knowing wrongdoers, as the Non-Compositional Account that I will now defend has it. I will proceed in two steps. Later on, I will defend a further account of the badness of motives. But first I will argue that we don't need Sarch's idea of composition.

To compare willfully ignorant and knowing wrongdoers, we need some principle on the basis of which they can be compared. As explained in Sect. 2, Sarch starts from CCP, according to which one's degree of blameworthiness is proportional to one's degree of confidence that one's conduct is wrong. On CCP, setting a building on fire while being fairly confident that a person is inside is worse than doing the same thing while merely thinking that there is a slight chance that a person might be inside. I won't deny that this verdict might be right. Yet, I don't think CCP should be regarded as a fundamental principle. For one might wonder: why is the agent who is less confident that a person is in the building less blameworthy than the agent who is more confident about this? As Sarch himself clarifies: "The latter, after all, appears to manifest greater disregard or disrespect for others than the former." (2014: 1063) I think this is on the right track. Yet it implies, which Sarch does not acknowledge, that we may skip CCP altogether and just focus on the disregard for others manifested by the two agents. ${ }^{15}$

Moreover, if we deny CCP as a starting point, we are also not committed to the idea of composition. After all, if we don't start from CCP, we don't need to say that willfully ignorant agents are less blameworthy for their ignorant acts, though they

\footnotetext{
$15 \mathrm{CCP}$, or something close to it, might still be derived as follows: (1) blameworthiness tracks disregard for others; (2) knowing (or more confident) wrongdoers have greater such disregard than willfully ignorant (or less confident) wrongdoers; therefore: (3) knowing (more confident) wrongdoers are more blameworthy than willfully ignorant (less confident) wrongdoers.
} 
may incur additional blameworthiness for their ignorance. Here's a first formulation of the non-compositional alternative ${ }^{16}$ :

$\mathrm{S}$ does $\mathrm{X}$ from a bad motive, and is blameworthy for wrongful $\mathrm{X}$ iff, ${ }^{17}$ and to the extent that, $\mathrm{X}$ is due to a disregard for the interests of others.

This account is non-compositional because it doesn't ask two separate questions concerning S's blameworthiness for her act and for her ignorance, but just one question concerning S's blameworthiness for her overall conduct, and whether it manifests a disregard for others. ${ }^{18}$ At this point, one might think that this can still be translated to a compositional account, namely one where one's blameworthiness is a function of the disregard manifested in one's ignorant act plus the disregard manifested in not informing oneself. Yet my account here is not compositional in this way, and in Sect. 6 I'll explain why.

Charlow has suggested such a criterion to defend ECT: "Someone who commits a criminal act [from willful ignorance] is probably as insensitive and indifferent to the criminality of his act as someone who actually believes he is acting criminally." (1992: 1417) Strictly speaking, Charlow is not speaking of disregard for the interests of others, but rather indifference to the criminality of one's conduct, though for the rest the idea seems to be the same. As Sarch (2014: 1055-1056) rightly comments, however, this can't establish ECT unless it has been shown that all willfully ignorant wrongdoers lack the same degree of indifference to the criminality of their acts as knowing wrongdoers. But, this seems too strong in light of the various willfully ignorant agents we have specified in Sect. 3. Sometimes willfully ignorant wrongdoers are indeed quite indifferent, though at other times they are merely lazy, weak, or confused.

Hence the question arises of how we can determine an agent's degree or amount of disregard for the interests of others. Sarch treats this notion as primitive and offers no explication of it. In particular, as we will see in Sect. 5, he refuses to understand the notion in counterfactual terms. Still, I think we need such a further explication, for we cannot apply the Non-Compositional Account with confidence without it.

Of course, some applications are more straightforward than others. If Noah wants to do the wrong thing, such as transporting people to concentration camps (in Conductor), then his disregard for the interests of his passengers is greater than if he

\footnotetext{
16 Inspiration for such an account can be found in the philosophy of law (cf. Alexander (2000: 931), according to which all criminal culpability can be explained in terms of "the basic moral vice of insufficient concern for the interests of others"), as well as quality of will approaches to moral responsibility (cf. Strawson (1962), according to which attributions of blameworthiness are "essentially reactions to the quality of others' wills towards us, as manifested in their behaviour: to their good or ill will or indifference or lack of concern"). See also the contributions in Robichaud and Wieland (2017), e.g. Björnsson (2017).

17 If one wants to derive excuses (cases of blamelessness) from such an account, the condition must be not only sufficient, but also necessary.

18 In principle, there can be a difference between the amount of disregard one has and the amount of disregard one manifests in particular acts (cf. Sarch 2017). For the purposes of this paper, I won't explore the implications of this difference, though it will prove relevant when we compare Will and Noah to counterparts who face circumstantial obstacles to doing the wrong thing.
} 
does not really want to do this, but lacks the strength to do the right thing. Also, if Will wants to preserve his lifestyle (in Flyer), then his disregard for the interests of future generations that might suffer from his ecological footprint is greater than if he had no strong selfish motive, but perhaps major psychological difficulties in recognizing the truth about his lifestyle.

Still, there are many other cases in which the comparison is less straightforward. What about a morally ignorant Noah who knows he is transporting people to concentration camps, though not that this is wrong (because he is a Nazi)? It is plausible to think he has a certain disregard for the interests of his passengers, though is his disregard greater or smaller than a comparable agent who does know that what he is doing is wrong? Comparisons between a Noah and a Will (rather than between two Noahs, or two Wills) are even trickier. Still, such comparisons are needed in order to evaluate ECT (i.e. the thesis which says something about both Will and Noah). Suppose we have a Noah who knows that his lifestyle is wrong, but keeps it up because he simply doesn't care about this, and a Will who willfully avoids information about this because he wants to preserve his lifestyle. Who has a greater disregard for the interests of future generations? Or might their degree of disregard be the same?

All in all, there are various tricky cases, and we need some measure of disregard for the interests of others. Does such disregard come in certain recognizable units? Normally, a good (albeit imperfect) measure for checking an agent's concern is to ask whether she exerted enough effort to do the right thing. ${ }^{19}$ Agents who exert more such effort have more regard for others than other agents who exert less. In the present debate, though, this measure seems to be of no use. As assumed from the outset, all variants of Will and Noah have easy options to inform themselves, and respecting the interests of others does not seem to require much effort. The differences between the agents are too subtle, and, as I will argue next, they might only be explainable in modal terms.

\section{Ignorance Counterfactual}

Let us take stock. So far I have suggested that ECT holds when the motives of knowing and willfully ignorant wrongdoers are equally bad. We have tried to approach this issue in terms of degrees of disregard for the interests of others. Yet, this approach proved to be imprecise, and not applicable enough. Next, I will defend a counterfactual approach to the badness of motives.

I will first discuss what I call the 'Ignorance Counterfactual'. In my view, to a certain extent this counterfactual is plausible, and can be defended against criticism, though in the end I'll opt for a different counterfactual. Generally, counterfactuals provide information about what agents would have done in slightly different circumstances. The Ignorance Counterfactual tells us something about the agent's conduct in the event she had not been ignorant, and the idea is that she acts from a

${ }^{19}$ For such a factor, cf. Sorensen (2010) and Douglas (2014). 
bad motive if she would still have been a wrongdoer in such a case. More precisely $^{20}$ :

Ignorance Counterfactual. S does X from a bad motive, and is blameworthy for wrongful $\mathrm{X}$, iff $\mathrm{S}$ would still have done $\mathrm{X}$ had $\mathrm{S}$ not been ignorant.

Example: in Flyer, Will acts from a bad motive if he would still have been a frequent flyer had he known about climate change. But his motives aren't so bad if his conduct is less robust, and he wouldn't have continued his lifestyle under full information. Or, in Tourist, Will acts from a bad motive if he would still have transported the weapons had he known about the contents of the suitcase. But again, his motives aren't so bad if he would not have done so under full information. ${ }^{21}$

Strictly speaking, the Ignorance Counterfactual comes in two versions. The first concerns ignorance about facts relevant to whether $\mathrm{X}$ is wrong. For example, facts about climate change are relevant to whether frequent flying is wrong. The second version also includes moral ignorance. Even if you know all the facts about climate change, and the relation between frequent flying and climate change, you might still be ignorant that frequent flying is wrong. Similarly, even if you know all the facts about the Holocaust, and the relation between your job transporting people and the Holocaust, you might still be ignorant that your transport is wrong, namely if you are a Nazi. On this version, the counterfactual asks what the agent would have done in cases where she is not morally ignorant in such a way.

Of course, counterfactuals come with certain epistemic obstacles. We do not always know what agents would have done in different circumstances. In Tourist, for example, if Will had not been ignorant, would he still have accepted the offer? It seems hard to tell. Still, I think these epistemic obstacles should not be overestimated. If Will's ignorance is due to mere laziness at the time, then it is likely that he would have acted better when he would have known better. Also, in some cases we have information about what the agent did in similar circumstances in the actual world. Perhaps Will refused to transport suitcases on earlier occasions when he didn't trust what was going on. At any rate, the point is that if you have such information, you'll be able to determine Will's motives.

As Luban (1999) and Michaels (1998) have suggested, the Ignorance Counterfactual gains some plausibility in the context of ECT. According to ECT, willfully ignorant wrongdoers should be treated the same as knowing wrongdoers, and the Ignorance Counterfactual basically checks whether the ignorance of the willfully ignorant wrongdoers makes any difference to their conduct (and so whether they might as well have been knowing wrongdoers).

Sarch has criticized this counterfactual defense of ECT. He offers general criticism as well as specific counterexamples, and I will offer a reply to both.

\footnotetext{
${ }^{20}$ This counterfactual, though not in the context of the badness of motives, has been mentioned in e.g. Zimmerman (1988: 79), Stratton-Lake (2000: 22), Rosen (2003: 62), Guerrero (2007: 62).

21 Note that we are still working under the assumption that the agent has reasonable opportunities to act otherwise (see Sect. 1). Without this assumption, the account might face counterexamples. In Conductor, for example, Will might not act from a bad motive if he can't quit his job, that is, even if he does know about the Holocaust.
} 
Strictly speaking, Sarch does not directly object to the Ignorance Counterfactual formulated above, but to the following account:

Consider $\mathrm{A}$ and her counterfactual self, $\mathrm{A}^{*}$, who are as similar as can be except for one difference noted below. Both $\mathrm{A}$ and $\mathrm{A} *$ perform a certain type of action, $\mathrm{X}$. A is in circumstances $\mathrm{C}$ and does $\mathrm{X}$ with mental state, $\mathrm{M}$. $\mathrm{A}^{*}$ is in $C^{*}$ (not $C$ ) and does $X$ with a more culpable mental state, $M^{*}{ }^{22}$ However, were $A$ in $C^{*}$, she would do $\mathrm{X}$ with $\mathrm{M}^{*}$ (just like $\mathrm{A}^{*}$ does). Moreover, suppose that $\mathrm{A}$ herself is responsible for the fact that she is in $\mathrm{C}$, not $\mathrm{C}^{*}$. On these suppositions, A is just as culpable as A*. (2014: 1059-1060)

Example: Will and Noah in Flyer. Both are frequent flyers, but Will does his flying in willful ignorance of climate change, while Noah does it with full knowledge of climate change. They are blameworthy to the same degree, according to the account just stated, if two conditions are met. First, it has to be true that if Will had known about climate change, he would still have been a frequent flyer. Second, Will himself has to be responsible for the fact that he is in a state of ignorance rather than a state of knowledge.

Sarch's general objection to this account is as follows: "the mental state one would have had under counterfactual circumstances, but actually lacked, cannot be the basis for how culpable one is for one's actual action. After all, one's counterfactual mental state did not produce the actual action." (2014: 1059) Thus, Will's blameworthiness for his actual flying behaviour cannot be determined on the basis of any counterfactual mental state, even if the latter might well have been his actual mental state, because such counterfactual states did not cause his actual behaviour.

In response, I agree that counterfactual mental states do not cause actual behaviour, and that we are interested in actual motives for actual behaviour. However, this does not exclude that the badness of one's actual motives covaries with certain counterfactuals. The idea is that one's actual motives are bad depending on how one acts in the counterfactual situation, where one does know what one is doing. And this is all that the counterfactual proposal is committed to saying. ${ }^{23}$

Recently, Sarch has stated his criticism of the counterfactual approach in slightly different terms:

Simons [2002: 264ff] points out that punishing on the basis of a counterfactual mental state that one would have acted on, but actually did not act on, amounts to punishing merely for character. This problem afflicts [the counterfactual approach] because it allows us to take willfully ignorant defendants who

\footnotetext{
22 According to Sarch's CCP principle, the mental state of knowledge is "more culpable" than the state of willful ignorance (see Sect. 2).

23 The counterfactual approach admits of different readings. On a first reading, one's actual motives are determined by one's counterfactual conduct. On a second reading, the order of priority is reversed: one's counterfactual conduct is a side-effect of one's actual motives (cf. Wieland 2017b: 4492). On a further, epistemological reading (which may be combined with one of the former readings), one's counterfactual conduct provides evidence for one's actual motives. These further details are important, though don't matter for my argument here.
} 
actually lacked knowledge to be just as culpable as knowing wrongdoers solely on the basis of how the former would have behaved under non-actual circumstances. [The counterfactual approach] thus ties the willfully ignorant defendant's culpability not to the mental state she actually acted with, but rather to a mental state she merely was willing to act with. (2016: 292)

In this passage, Sarch makes two, related claims. First claim: the counterfactual approach focuses on the mental state that the agent was willing to act with, though did not actually act with. Second claim: the counterfactual approach punishes agents merely for their character rather than for the acts they actually perform. Consider for example the idea that, in Tourist, Will would be as blameworthy as Noah given that Will had still transported the weapons even when he knew about the contents of the suitcase. In terms of this example, Sarch's objections are as follows. First, the counterfactual approach mistakenly focuses on the mental state Will was willing to act with (namely: knowledge), while it should focus on the mental state he actually acted with (namely: willful ignorance). Second, by focusing on a mental state that Will was only willing to act with, the counterfactual approach does not punish Will for his action (of transporting weapons, in this case), but rather for his character. Will has a bad character, and may be punishable for that if he proves willing to transport drugs in full knowledge of what he's doing.

These are serious worries, but don't undermine the counterfactual approach I'm defending here. I'll respond to both of Sarch's claims. First: the approach doesn't determine the blameworthiness of the given agents on the basis of their mental states with which they act (as Sarch's account has it), but rather on the basis of the motives on which they act. These may come apart. While Will and Noah act with different mental states (namely of willful ignorance and knowledge respectively), they may well act on the basis of the same kind of motive. For example, in Tourist both Will and Noah may be motivated by the desire to make easy money when they both accept the offer by the stranger and transport the suitcase. ${ }^{24}$ Note that such desires constitute their actual motives, i.e. motives on which they actually act, not motives on which they'd be willing to act but do not actually. And if their actual motives are the same, they may well be equally blameworthy for their conduct insofar as the counterfactual approach is concerned.

My second point: given that the counterfactual approach still operates with actual motives on which agents act, it doesn't follow that it only punishes for character. For example, it does not merely state that Will is blameworthy for his willingness to commit the crime even if he knew about the contents of the suitcase. Rather, it states that Will is blameworthy for transporting the suitcase because he acts on a desire to make easy money (rather than a desire, for instance, to save the relationship with a family member, as in Overly Trusting Parent). What's counterfactual about the

\footnotetext{
24 Again, when I speak of motives, I am referring to facts that explain people's conduct, even if these are not fully obvious to the agent herself (see Sect. 3).
} 
account, as per my response to the first statement of Sarch's criticism given above, is that such desires covary with certain counterfactuals. ${ }^{25}$

Hence, I take it that Sarch's general criticism doesn't undermine the counterfactual approach defended here. Apart from his general criticism, Sarch also develops specific counterexamples. In my view, there are indeed serious problem cases, which I'll answer in the following section. First, we'll need to see which cases are problematic and which not. Here's Sarch's first case:

Smokey the Bear. Suppose that Joe gets irrationally angry when he sees Smokey the Bear signs in the park. (He had some traumatic encounters with people in bear costumes as a child.) One day, he heads to the park to barbeque with friends. Suppose that if he were to see a Smokey the Bear sign on this trip, it would cause him such anger that he would intentionally refrain from dousing his campfire in the hopes that it will lead to a forest fire (which, let us stipulate, it would). In fact, however, Joe knows he tends to get into trouble when he sees Smokey the Bear signs, so he now tries to avoid the sight of them. Accordingly, as he is driving through the entrance gate to the park en route to his barbeque party, he stares intently at his GPS in order to avoid seeing any Smokey the Bear signs. As a result, he does not actually see any Smokey the Bear signs and avoids getting angry. Nonetheless, he is so stuffed when he leaves the barbeque that he simply forgets to douse his campfire and it causes a forest fire. (2014: 1060)

This case appears to pose a problem for the Ignorance Counterfactual. For if Joe had not been ignorant, he would still have caused the forest fire. Yet, we would not want to say that Joe's motives are bad.

The first thing to note about this case is that Joe's motive for not informing himself and his motive for not dousing the campfire come apart. He didn't look at the signs because he didn't want to become angry. In contrast, he didn't douse the campfire simply because he forgot to do it (and we may suppose that he would have done it if hadn't forgotten it). This mismatch is important. For it reveals that the case does not constitute a counterexample to the Ignorance Counterfactual after all. When it comes to the Ignorance Counterfactual, we are not interested in counterfactual cases where Joe is aware or unaware of random things (such as Smokey the Bear signs). Rather, we are only interested in counterfactual cases where he is aware of all the facts that are relevant as to whether failing to douse the campfire is wrong. Had Joe not been ignorant that he forgot to douse the campfire, he would not have failed to douse the campfire, and that is why his motives aren't bad. $^{26}$

\footnotetext{
25 Philosophers often distinguish between attributability and accountability (cf. Watson 1996; Wieland 2017b: 4487-4491), where attributability concerns an evaluation of the agent's character as it is manifested in her conduct, while accountability incorporates a fairness condition: agents are accountable only if they could fairly have been expected to do better. In this paper, I'm focusing on the attributability discussion: what matters here are the badness of one's motives on which one acts, and not whether one could fairly have been expected to have and act from better motives.

26 At least insofar as we can see on the basis of the case description. To determine in full detail whether his motives are bad would require that we know more about why he forgot to douse the campfire.
} 
Yet this does not mean, of course, that no variant of this case can work. Here's a revised case $^{27}$ :

Smokey the Bear Revised. As before, Joe actually just forgets about the campfire and negligently fails to douse it. However, suppose it's also true that due to Joe's painful memories of learning the rules of campfire safety, any thoughts of campfire safety cause Joe to fly into a rage. Thus, if he had been aware of the need to douse the campfire, this would have caused him to become uncontrollably angry - so much so that he would have used the fire to burn down the park.

This counterexample is successful. Had Joe been aware that he needed to douse the campfire, he would still have caused the forest fire. Yet, we would not want to say that Joe's motives for causing the fire are bad. After all, in the actual case, he merely forgets to douse it. And so the Ignorance Counterfactual can't be right.

It will be instructive to consider a second problem case, i.e. a variant of Overly Trusting Parent:

Overly Trusting Parent Revised. Now add just one small detail: Patty is so concerned not to damage her recently rebuilt relationship with her son that she would have agreed to drive the package across town even if her son had told her it contained drugs. In fact, however, her son does not tell her this. So, she proceeds to drive the crate across town without looking inside - that is, in willful ignorance. Thus, Patty in the revised case - "Patty 2" - performs exactly the same action as Patty in the original version of Overly Trusting Parent - "Patty 1." Although we know Patty 2 would have been willing to behave the same way even if given full-fledged knowledge of what the crate contained, this is not actually the mental state she acted with. (Sarch 2016: 293)

The counterexample to the Ignorance Counterfactual is this: Patty would still have committed the crime even if she had known that she would be transporting drugs. Still, we wouldn't want to say that she acts from a bad motive. For, as before, she is merely motivated by a desire to save the relationship with her son. Hence, even though I disagree with Sarch's criticism of the counterfactual approach in general (as explained in this section), I do agree that cases such as Smokey the Bear Revised and Overly Trusting Parent Revised pose a problem, and need to be accounted for. ${ }^{28}$

\footnotetext{
27 Suggested to me by a referee. As the referee points out, these problem cases arise when the counterfactual is satisfied only "accidentally", namely in a way that has nothing to do with the agent's motives.

28 Both cases form a counterexample to the sufficiency of the counterfactual (committing the act even with full information is insufficient for bad motives). Sarch (2016: 294) also challenges its necessity (that committing the act even with full information is neither necessary for bad motives).
} 


\section{Difficulty Counterfactual}

As I see it, the Ignorance Counterfactual admits of counterexamples due to its binary character. Either one satisfies the counterfactual "if S had not been ignorant, then S would still have done X", or one fails to satisfy it. One can't be said to satisfy it only to a certain degree, or so it seems. On this reading, just a single case where a counterpart would still have done the act with full information (such as Joe and Patty in the revised cases just discussed) can cause problems.

But I don't think this binary reading is the most plausible way to take the Ignorance Counterfactual. First of all, the badness of motives comes in degrees, so if the Ignorance Counterfactual doesn't come in degrees, it can't be fully adequate. Yet, there's no reason to think that the counterfactual can't be satisfied to a certain degree. If a significant portion of non-ignorant counterparts of $\mathrm{S}$ still fail to commit the wrongful act $\mathrm{X}$ (even though some of them do $\mathrm{X}$ ), then one might still want to say that the motives on which S did X aren't so bad. Patty's motives, for instance, aren't so bad if many of her non-ignorant counterparts try to find another way to save the relationship with their son (and refuse to transport the drugs). This holds whether or not there are a few worlds in which she is non-ignorant and does transport the drugs. Hence, on this reading of the Ignorance Counterfactual, the problem cases from the previous section form no threat.

Still, even if such a reading could work, I would agree that it doesn't provide the most plausible story of why one should think that Patty's motives aren't so bad in the Overly Trusting Parent case. Rather, the most plausible story of why Patty's motives aren't bad, it seems to me, is that she wouldn't commit the crime if her son were not a drug dealer (or if there were no problems of trust between them). More generally, the idea would be that $\mathrm{S}$ doesn't do $\mathrm{X}$ from a bad motive if it's difficult for $S$ to do the right thing, and if she would do the right thing in easier circumstances. In contrast, $\mathrm{S}$ does do $\mathrm{X}$ from a bad motive if she would do $\mathrm{X}$ even if it were easy for her to do the right thing. We can say that Patty acts from a bad motive if she would still have transported the drugs even if her son were not a drug dealer.

Here is the account in full ${ }^{29}$ :

Difficulty Counterfactual. S does X from a bad motive, and is blameworthy for wrongful $\mathrm{X}$, iff, and to the extent that, $\mathrm{S}$ would still have done $\mathrm{X}$ even if it had been easier to do the right thing.

This time, the counterfactual tells us something about the agent's conduct not in the event that she was not ignorant, but in the event that it would have been easier for her to do the right thing. The idea is that she acts from a bad motive if she would

\footnotetext{
29 This counterfactual is due to Arpaly (2003: 84-93), who endorses the criterion not only in terms of blameworthiness, but also in terms of praiseworthiness, and refers to various philanthropists to illustrate it. On the one hand, there is a diehard philanthropist who donates a great deal of money to help others in need, and would do the same even if she were to have far less money herself. On the other hand, there are fair-weather and capricious philanthropists who do donate in some situations, but not in many others, and hence are less praiseworthy than the diehard philanthropist. For criticism of this idea, cf. Markovits (2010: 214); for a defense, cf. Sliwa (2016).
} 
still have done wrong in such a case. I have applied this idea to the Overly Trusting Parent case, though it's instructive to consider further examples. In Flyer, Will acts from a bad motive if he would still have been a frequent flyer even if his friends were climate change activists who organized awesome parties in his own city. In Conductor, Will acts from a bad motive if he would still have transported people to concentration camps even if there were no dictatorial regime (and if it were much easier and less dangerous and stressful to protest).

This is not the place to offer a full account of when it's easier for agents to do the right thing, though in each of the applications considered above I have varied the circumstances of the agents. In Overly Trusting Parent, for example, I changed the family situation. It's easier for Patty to do the right thing and refuse to transport the package without checking it because, this time, doing so would pose no threat to the relationship with her son. In Conductor, I've done the same: I varied Will's circumstances by imagining it's no longer a time of war. In Flyer, I even added a source of difficulty for doing the wrong thing, namely that Will's friends are climate change activists. It's easier for Will to do the right thing (and fly less) because it's more difficult to do the wrong thing (namely, something that one's friends condemn). ${ }^{30}$

The Ignorance Counterfactual is supposed to track whether S's conduct may be attributable to her ignorance rather than to S's motives (namely by varying S's ignorance and keeping the rest fixed). ${ }^{31}$ The Difficulty Counterfactual, in contrast, tracks whether S's conduct may be attributable to the circumstances rather than to S's motives (and it does so by varying S's circumstances, keeping the rest fixed). Both accounts link the badness of motives to the robustness of the wrongful conduct. One's motives are less bad if one's crime is less robust (among counterfactual cases). In Overly Trusting Parent, Patty's motives aren't bad. She'd have nothing to do with the transport of drugs if the situation with her son were better. The same may hold for many drug dealers: they wouldn't have committed a crime had their circumstances been better. Not so, however, for wrongdoers who would continue to do what they're doing even in cases where they don't really need the money (as might well be the case in Tourist).

In principle, one may use both counterfactuals to evaluate S's motives. ${ }^{32}$ Still, I propose that the Difficulty Counterfactual is the better option. After all, as suggested, it offers a more satisfactory explanation of why certain Noahs and Wills are more blameworthy than others (or equally blameworthy). In addition, it can also account for the phenomenon of degrees, given that one may satisfy it to a certain extent. I'll consider both points in turn.

Compare Noah who wants to do the wrong thing with Noah who lacks the strength to do the right thing. Why does the latter Noah act from better motives (and is less blameworthy than the former)? The Difficulty Counterfactual has a

\footnotetext{
${ }^{30}$ For a discussion of potentially relevant sources of difficulty, cf. Wieland (2017b: 4484-4486).

31 In these terms, Sarch's account tracks whether S's conduct may be attributable to justified reasons to remain ignorant rather than to a disregard for the interests of others. In contrast to the Ignorance Counterfactual, however, Sarch (2016) does not attempt to do this by varying S's ignorance and considering counterfactual situations, but by evaluating the agent's justification for remaining ignorant.

32 In that case, one should take the separate counterfactuals as merely sufficient for bad motives.
} 
straightforward explanation. Namely, Noah who isn't strong enough to do the right thing in the actual case would do the right thing in counterfactual situations where doing the right thing is easier (while this does not apply to Noah who wants to do the wrong thing). Or compare Will who wants to preserve his lifestyle with Will who was simply confused at the time. If the circumstances were less complicated, and it was totally clear to Will that he had to inform himself in order to do the right thing, then the latter Will would have do so (while this does not apply to the Will who wants to preserve his lifestyle).

One might even compare Noahs and Wills. Consider Noah who is indifferent about the fact that he transports weapons and Will who wants to benefit from the transport. If both fail to do the right thing in all the same counterfactual situations where things are easier, then they act from equally bad motives and are equally blameworthy.

An account of degrees can be based on this. The rough idea would be as follows. ${ }^{33} \mathrm{~S}$ acts from worse motives than another agent $\mathrm{S}^{*}$ iff compared to $\mathrm{S}^{*}, \mathrm{~S}$ does the right thing in less counterfactual situations where things are easier (keeping fixed other relevant factors); and $\mathrm{S}$ and $\mathrm{S}^{*}$ act from equally bad motives iff $\mathrm{S}$ and $\mathrm{S}^{*}$ fail to do the right thing in the same number of counterfactual situations where things are easier. On this account, the idea is that ECT holds whenever Noah and Will satisfy the Difficulty Counterfactual to the same extent. ${ }^{34}$

Now with the full account at our disposal, let's finally return to the compositionality issue. Sarch's account is compositional, as stated, because it asks two separate questions: one about S's degree of blameworthiness for her ignorant act, the other about her degree of blameworthiness for her ignorance (or for failing in a duty of investigation). S's overall blameworthiness, it states, is a composite of these two. In Tourist, Will may be as blameworthy as Noah, for even though he's less blameworthy for his ignorant act, he may incur additional blameworthiness for his ignorance (which may add up to Noah's degree of blameworthiness). My account isn't compositional in this way, since it does not assign any special role to blameworthiness for ignorance. It merely asks about the motive on which $\mathrm{S}$ performs the act (whether it be an ignorant act or not), and then further analyses the badness of these motives in counterfactual terms. Will is as blameworthy as Noah if both act from similarly bad motives, which means, on the account proposed here, that their wrongful conduct is similarly robust.

\section{Coda}

Is ECT true and are willfully ignorant wrongdoers as blameworthy as knowing wrongdoers, as many legal systems assume? Sarch has defended a restricted version of ECT, which I have dubbed the Compositional Account. On his view, ECT is true

\footnotetext{
33 For a possible worlds account, albeit in the context of a different theory of moral responsibility, cf. Coates and Swenson (2013).

34 Such counterfactual information may not always be readily available, but, as before, the proposal is that if we have such information, we can determine the badness of one's motives, and indeed the degree of one's blameworthiness.
} 
whenever willfully ignorant agents incur sufficient additional blameworthiness for their ignorance. In this paper, I have defended an alternative view: the NonCompositional Account. On this view, ECT is true whenever the motives of willfully ignorant and knowing wrongdoers are equally bad. Moreover, I have defended a counterfactual criterion to evaluate the badness of motives.

Both accounts discussed in the foregoing focus exclusively on the backwardlooking issue of whether an agent deserves blame for what she has done. The question remains of whether there are interesting links to the forward-looking issue of whether agents should also be punished in order to protect society from them, or to rehabilitate them. In Tourist, Conductor, and Flyer, should we punish Noah and Will for such additional reasons? I will conclude this paper with two speculative hypotheses. On the one hand, agents who act from bad motives would still do the wrong thing even if circumstances were easier (as per the Difficulty Counterfactual), and one might want to protect society from such agents (and punish them for this reason). On the other hand, agents who act from moderate motives will do the right thing if the circumstances are easier, and one might want to punish them in order to motivate them to do better in the future. Whether these hypotheses can be validated deserves further attention.

Acknowledgements Special thanks to a reviewer of the journal for extensive feedback. This paper has been written in the context of the research project 'We should know better. An inquiry at the crossroads of ethics and epistemology' supported by the Netherlands Organization for Scientific Research.

Open Access This article is distributed under the terms of the Creative Commons Attribution 4.0 International License (http://creativecommons.org/licenses/by/4.0/), which permits unrestricted use, distribution, and reproduction in any medium, provided you give appropriate credit to the original author(s) and the source, provide a link to the Creative Commons license, and indicate if changes were made.

\section{References}

Alexander, L. (2000). Insufficient concern: A unified conception of criminal culpability. California Law Review, 88, 931-954.

Arpaly, N. (2003). Unprincipled virtue. An inquiry into moral agency. Oxford: OUP.

Björnsson, G. (2017). Explaining (away) the epistemic condition on moral responsibility. In P. Robichaud \& J. W. Wieland (Eds.), Responsibility: The epistemic condition (Chap. 8). Oxford: OUP.

Charlow, R. (1992). Willful ignorance and criminal culpability. Texas Law Review, 70, 1351-1429.

Coates, J., \& Swenson, P. (2013). Reasons-responsiveness and degrees of responsibility. Philosophical Studies, 165, 629-645.

Douglas, T. (2014). The relationship between effort and moral worth: Three amendments to Sorensen's model. Ethical Theory \& Moral Practice, 17, 325-334.

Guerrero, A. A. (2007). Don't know, don't kill: Moral ignorance, culpability, and caution. Philosophical Studies, 136, 59-97.

Hellman, D. (2009). Willfully blind for good reason. Criminal Law and Philosophy, 3, 301-316.

Husak, D. N., \& Callender, C. A. (1994). Wilful ignorance, knowledge, and the 'equal culpability' thesis. Wisconsin Law Review, 1, 29-69.

Luban, D. (1999). Contrived ignorance. Georgetown Law Journal, 87, 957-980.

Markovits, J. (2010). Acting for the right reasons. Philosophical Review, 119, 201-242. 
Michaels, A. C. (1998). Acceptance: The missing mental state. Southern California Law Review, 71, 953-1035.

Moody-Adams, M. M. (1994). Culture, responsibility, and affected ignorance. Ethics, 104, 291-309.

Robichaud, P., \& Wieland, J. W. (Eds.). (2017). Responsibility: The epistemic condition. Oxford: OUP. Rosen, G. (2003). Culpability and ignorance. Proceedings of the Aristotelian Society, 103, 61-84.

Sarch, A. F. (2014). Willful ignorance, culpability and the criminal law. St. John's Law Review, 88, 1023-1101.

Sarch, A. F. (2016). Equal culpability and the scope of the willful ignorance doctrine. Legal Theory, 22, 276-311.

Sarch, A. F. (2017). Who cares what you think? Criminal culpability and the irrelevance of unmanifested mental states. Law and Philosophy, 36, 707-750.

Simons, K. W. (2002). Does punishment for culpable indifference simply punish for bad character? Examining the requisite connection between mens rea and actus reus. Buffalo Criminal Law Review, 6, 219-315.

Sliwa, P. (2016). Moral worth and moral knowledge. Philosophy and Phenomenological Research, 93, 393-418.

Sorensen, K. (2010). Effort and moral worth. Ethical Theory \& Moral Practice, 13, 89-109.

Stratton-Lake, P. (2000). Kant, duty, and moral worth. London: Routledge.

Strawson, P. F. (1962). Freedom and resentment. Proceedings of the British Academy, 48, 187-211.

Watson, G. (1996). Two faces of responsibility. Philosophical Topics, 24, 227-248.

Wieland, J. W. (2017a). Willful ignorance. Ethical Theory \& Moral Practice, 20, 105-119.

Wieland, J. W. (2017b). Responsibility for strategic ignorance. Synthese, 194, 4477-4497.

Zimmerman, M. J. (1988). An essay on moral responsibility. Lanham: Rowman \& Littlefield. 